\title{
Mulch Effects on Three Highbush Blueberry Cultivars Grown in Container
}

\author{
Sabin MOLNAR, Viorel MITRE* , Vasile MELNIC, Andreea ANDRECAN, Tabita LISANDRU, Maria CODREA \\ University of Agricultural Sciences and Veterinary Medicine, Faculty of Horticulture, 3-5 Manastur \\ Street, Cluj-Napoca 400372, Romania \\ *corresponding author, e-mail: viorel.mitre@usamvcluj.ro
}

BulletinUASVM Horticulture 76(2) / 2019

Print ISSN 1843-5254, Electronic ISSN 1843-5394

DOI:10.15835/buasvmcn-hort: 2019.0029

\begin{abstract}
Weed problems were reported in almost all production areas, and management of competing unwanted vegetation has long been an issue for commercial growers all around the world. A field trial was set up in 2016 in Bologa, Cluj county, Romania, in order to examine the influence that different mulches have on weed control, crop growth, yield and soil properties. Weed management is critical for successful production of blueberries. The use of herbicides is becoming increasingly limited, the cost and availability of manual labor are prohibitive factors. There was little research comparing different production strategies in container grown blueberries. The main objective was finding a cost effective weed suppression method that increases yield, promotes vegetative growth and fruit quality. Organic matter $(\mathrm{OM})$ was $6 \%$ higher in pine bark treatment compared with weed mat, the pH was not influenced in a significant way by any of the treatments. The number of shoots was higher in pine bark treatment, 1.67 on average, compared to weed mat treatment where the number of shoots was 1.45 this might lead to an increase of production in the following years for pine bark.
\end{abstract}

Keywords: blueberry yield, fruit quality, organic matter, weed control, Vaccinium corymbosum

\section{Introduction}

Management of competing vegetation has long been a challenge in agricultural production and current problems persist, even with the widespread use of herbicides. In a survey of commercial North American blueberry producers, weed problems were cited in almost all production areas (Strik, 2006). In addition to weed management, availability and affordability of fertilizers are of critical importance for the economical production of organic blueberry (Strik, 2014). Weed mat or landscape fabric, an inert mulch approved for use as a weed barrier by the USDA Organic National Program (USDA-AMS-NOP, 2011) is an alternative to sawdust mulch. Weed mat is used widely in fruit tree orchards, mainly because of its effectiveness for weed control, although weeds appear in the planting hole and removal by hand may be required. (Julian et al., 2012).

The number of flower buds per bush was positively correlated with weed control, attributed to the negative effect of reduced plant vigor on flower bud formation (Burkhard et al., 2009).

All fresh mulches inhibited germination of lettuce seed, and although variable in concentration, all mulches contained hydroxylated aromatic compounds that could have caused these allelopathic effects. After 9 months and 1 year, pine straw and GRU still exhibited allelopathic effects on germination (Duryea et al., 1999). Adding organic amendment is a usual practice in highbush blueberry culture. Materials such as pine bark, peat and sawdust are commonly used 
as a preplant soil amendment, it is commonly used in new fields to increase the organic matter content of mineral soils, promote uniformity of root distribution and increase soil waterholding capacity (Burkhard et al., 2009). There is a wide range of cultivars available for growers that produce fruits in the earliest period ('Duke') mid season 'Bluecrop' to the latest ('Aurora').

\section{Materials and methods}

The research has been carried out at an experimental plot in Bologa $\left(46^{\circ} 52^{\prime} 56^{\prime \prime} \mathrm{N}\right.$ $22^{\circ} 52^{\prime} 49^{\prime \prime} \mathrm{E}$ ), Cluj county, Romania. The field trial was set up in spring of 2016.

The plants were produced by a local nursery, plants were taken out of 1.5 liters pots, with a beautiful rooting system, they were planted in containers with a $40 \mathrm{~L}$ volume, and were filled with a substrate of 2:1:1, loamy acidic soil, acidic peat moss and sand. The plants were spaced 0.9 $\mathrm{m}$ intra-row and $2.0 \mathrm{~m}$ apart giving a density of 5555 plants/ha. The experiment was a bifactorial model with first factor mulching type with two graduations: pine bark and weed mat, the second factor was the cultivar with three graduations ('Duke', 'Bluecrop', 'Aurora'). Results were collected in year of 2017-2018.

There were 18 treatments for this study comprised of 6 variants $(2 \times 3)$ in three replications.

Field management: Plants were pruned in such manner that equilibrium between vegetative growth and fruiting was promoted. All fruit buds were removed from the plants during spring of 2016. Any unwanted vegetation that appeared near the plant in the weed mat treatment and later in pine bark treatment was immediately removed by hand. Plants were irrigated 3 times a day with a total of $2 \mathrm{~L} /$ plant, using 4 drip emitters for each plant. Weed mat was applied before planting and it was cut in such way that it offered a space of 14 $\mathrm{cm}$ in diameter for the plant to grow new shoots. Pine bark was added in a 6-cm thick layer after the planting and was distributed evenly among the soil surface from the container. Data was collected regarding the number of new shoots, length of shoots, total yield and fruit characteristics like berry weight, fruit firmness, total soluble solids also soil characteristics was of interest, where soil $\mathrm{pH}$ and soil organic matter were tracked and measured. For the interpretation of the results it was used an analysis of variance respectively
Duncan's Test, in order to determine the significant differences.

\section{Results and discussions}

A pool soil sample was collected for analyses before planting and one soil sample for each treatment after two years, in order to assess the $\mathrm{pH}$ and organic matter. The $\mathrm{pH}$ increased slightly under both treatments, but without significant difference between the two treatments, thus, according to this study pine bark does not affect soil $\mathrm{pH}$. Pine bark should have a natural $\mathrm{pH}$ between and 5.0, ideal for blueberries. Several sources disagree whether the $\mathrm{pH}$ goes up or down slightly with decomposition (Gerard et al., 2009). Regarding the organic matter, there was a significant difference between pine bark and weed mat, the highest value of was registered under pine bark treatment $2.39 \%$ compared with $2.26 \%$ under weed mat.

According to Table 1, weed suppression efficacy was higher under pine bark treatment, due to the fact that the whole surface of soil was covered, where under weed mat, was left a space for new shoots to grow, which also lead to an increase of weeds/plant thus leading to an increase of cost for time consumed in order to remove each weed.

Other authors found that cost of weed management is higher under organic mulch, when the organic mulch is represented by compost or sawdust (Larco, 2010). Results confirmed by other studies made in organic orchards (Julian et al., 2012). These different results may come from the form of organic mulch that was being used. Pine bark may also cause greater weed number if it is has begun to decompose or if it has weeds seed in it.

Table 2 shows the influence of mulch and the cultivar on average number of shoots. 'Bluecrop' had a higher statistically assured number of shoots, compared with 'Duke' and 'Aurora'. Treatment significantly affected growth, plants under pine bark showed higher number of shoots, due to the higher organic matter or due to less stress of water and temperature, advantages given by the organic mulch.

Regarding the average length of shoots there were no statistically assured differences between weed mat and pine bark, results confirmed by others authors like (Merwe, 2012) who didn't find any significant differences on apple trees variety 'Cripps' and 'Pink'. In this experiment 'Bluecrop' 
Table 1. The influence of mulch and the cultivar on average number of weeds (2017 - 2018)

\begin{tabular}{lccc}
\hline \multirow{2}{*}{ Cultivar } & \multicolumn{3}{c}{ Treatment } \\
\cline { 2 - 4 } & Pine bark & Weed mat & Mean of cultivar \\
\hline Duke & $0,80 \mathrm{~b}$ & $5,40 \mathrm{a}$ & $3,10 \mathrm{M}$ \\
\hline Bluecrop & $1,00 \mathrm{~b}$ & $5,25 \mathrm{a}$ & $3,13 \mathrm{M}$ \\
\hline Aurora & $1,15 \mathrm{~b}$ & $5,05 \mathrm{a}$ & $3,10 \mathrm{M}$ \\
\hline Mean of treatment & $0,98 \mathrm{~B}$ & $5,23 \mathrm{~A}$ & \\
\hline
\end{tabular}

DS $5 \%$ Cultivar $=0.8-.09$

DS $5 \%$ Treatment $=1,6-1,69$

DS $5 \%$ Interaction Cultivar $\times$ Mulch $=7.22-8.12$

Table 2. The influence of mulch and the cultivar on average number of shoots (2017 - 2018)

\begin{tabular}{lccc}
\hline \multirow{2}{*}{ Cultivar } & \multicolumn{3}{c}{ Treatment } \\
\cline { 2 - 4 } & Pine bark & Weed mat & Mean of cultivar \\
\hline Duke & $1,55 \mathrm{a}$ & $1,25 \mathrm{a}$ & $1,40 \mathrm{O}$ \\
\hline Bluecrop & $2,00 \mathrm{a}$ & $1,70 \mathrm{a}$ & $1,85 \mathrm{M}$ \\
\hline Aurora & $1,45 \mathrm{a}$ & $1,40 \mathrm{a}$ & $1,43 \mathrm{O}$ \\
\hline Mean of treatment & $1,67 \mathrm{~A}$ & $1,45 \mathrm{~B}$ & \\
\hline DS 5 \% Cultivar $=1.5-1.6$ & & & \\
DS 5 \% Treatment $=2.94-3.09$ & & \\
DS 5 \% Interaction Cultivar $\times$ Mulch $=13.22-14.87$
\end{tabular}

Table 3. The influence of mulch and the cultivar on average length of shoots (cm) (2017 - 2018)

\begin{tabular}{lccc}
\hline \multirow{2}{*}{ Cultivar } & \multicolumn{3}{c}{ Treatment } \\
\cline { 2 - 4 } & Pine bark & Weed mat & Mean of cultivar \\
\hline Duke & $34,00 \mathrm{a}$ & $30,15 \mathrm{a}$ & $32,08 \mathrm{O}$ \\
\hline Bluecrop & $43,70 \mathrm{~b}$ & $40,45 \mathrm{~b}$ & $42,08 \mathrm{M}$ \\
\hline Aurora & $32,05 \mathrm{a}$ & $31,40 \mathrm{a}$ & $31,73 \mathrm{O}$ \\
\hline Mean of treatment & $36,58 \mathrm{~A}$ & $34,00 \mathrm{~A}$ & \\
\hline
\end{tabular}

DS $5 \%$ Cultivar $=1.97-3.79$

DS $5 \%$ Treatment $=3.94-6.22$

DS $5 \%$ Interaction Cultivar $\times$ Mulch $=7.32-13.63$

surpassed 'Duke' and 'Aurora' having a length of shoots on average of $42.08 \mathrm{~cm}$, this shows that 'Bluecrop' is a more vigorous cultivar than the other two.

Cox's experiment in 2009 have led to the following result that pine bark increased the canopy of blueberry plants in one site out of three but in the other two there were similar results on plants growth with no significant differences.

Alber, in 2010 showed that the plant growth and yield after pruning depends significantly on the growth medium. In the present study the best results were obtained in weed mat treatment, $1.56 \mathrm{~kg} /$ plant, the biggest yield was obtained on 'Bluecrop', followed by 'Aurora' and 'Duke'. Similar 
Table 4. The influence of mulch and the cultivar on yield (kg) (2017 - 2018)

\begin{tabular}{lccc}
\hline \multirow{2}{*}{ Cultivar } & \multicolumn{3}{c}{ Treatment } \\
\cline { 2 - 4 } & Pine bark & Weed mat & Mean of cultivar \\
\hline Duke & $1,26 \mathrm{a}$ & $1,46 \mathrm{a}$ & $1,36 \mathrm{O}$ \\
\hline Bluecrop & $1,60 \mathrm{~b}$ & $1,76 \mathrm{~b}$ & $1,68 \mathrm{M}$ \\
\hline Aurora & $1,39 \mathrm{a}$ & $1,47 \mathrm{a}$ & $1,43 \mathrm{~N}$ \\
\hline Mean of treatment & $1,41 \mathrm{~B}$ & $1,56 \mathrm{~A}$ & \\
\hline DS 5 \% Cultivar $=0.2-0.2$ & & & \\
DS 5 \% Treatment $=0.41-0.43$ & & \\
DS 5 \% Interaction Cultivar $\times$ Mulch $=1.86-2.09$
\end{tabular}

Table 5. The influence of mulch and the cultivar on berry weight (g) (2017 - 2018)

\begin{tabular}{lccc}
\hline \multirow{2}{*}{ Cultivar } & \multicolumn{3}{c}{ Treatment } \\
\cline { 2 - 4 } & Pine bark & Weed mat & Mean of cultivar \\
\hline Duke & $1,88 \mathrm{a}$ & $2,03 \mathrm{a}$ & $1,95 \mathrm{~N}$ \\
\hline Bluecrop & $1,86 \mathrm{a}$ & $2,03 \mathrm{a}$ & $1,94 \mathrm{~N}$ \\
\hline Aurora & $1,93 \mathrm{a}$ & $2,13 \mathrm{a}$ & $2,03 \mathrm{M}$ \\
\hline Mean of treatment & $1,89 \mathrm{~B}$ & $2,06 \mathrm{~A}$ \\
\hline & & & \\
DS 5 \% Cultivar $=0.4-0.4$ & & \\
DS 5 \% Treatment $=0.73-0.77$ \\
DS 5 \% Interaction Cultivar $\times$ Mulch $=3.28-3.69$
\end{tabular}

Table 6. The influence of mulch and the cultivar on fruit firmness (N) $(2017-2018)$

\begin{tabular}{lccc}
\hline \multirow{2}{*}{ Cultivar } & \multicolumn{3}{c}{ Treatment } \\
\cline { 2 - 4 } & Pine bark & Weed mat & Mean of cultivar \\
\hline Duke & $18,09 \mathrm{~b}$ & $19,05 \mathrm{a}$ & $18,57 \mathrm{M}$ \\
\hline Bluecrop & $14,92 \mathrm{c}$ & $15,41 \mathrm{ab}$ & $15,17 \mathrm{~N}$ \\
\hline Aurora & $18,12 \mathrm{~b}$ & $18,52 \mathrm{~b}$ & $18,32 \mathrm{M}$ \\
\hline Mean of treatment & $17,04 \mathrm{~A}$ & $17,66 \mathrm{~A}$ & \\
\hline
\end{tabular}

DS $5 \%$ Cultivar $=2.91-3.15$

DS $5 \%$ Treatment $=5.82-6.12$

DS $5 \%$ Interaction Cultivar $\times$ Mulch $=2.01-2.94$

results were obtained by Larco et al. in 2013, where weed mat outperformed organic mulches by $36 \%$.

The average berry weight as shown in Table 5 was greater under weed mat treatment, with 'Aurora' showing better results. This increased weight and being the latest cultivar that ripens could be very beneficial for commercial growers, looking for the best price of the season. While in other studies 'Duke' performed better under organic mulch treatment, the variety 'Liberty' shown better results under weed mat, mulch effects on berry weight are complex as a result of differences in yield/plant (Larco et al. 2013).

Similar results, as shown in Table 6 was found by Merwe et al., 2012. Mulch does not have 
Table 7. The influence of mulch and the cultivar on Total Soluble Solids (Brix $\left.{ }^{\circ}\right)(2017-2018)$

\begin{tabular}{lccc}
\hline \multirow{2}{*}{ Cultivar } & \multicolumn{3}{c}{ Treatment } \\
\cline { 2 - 4 } & Pine bark & Weed mat & Mean of cultivar \\
\hline Duke & $14,35 \mathrm{ab}$ & $13,95 \mathrm{~b}$ & $14,15 \mathrm{~B}$ \\
\hline Bluecrop & $16,95 \mathrm{a}$ & $16,60 \mathrm{a}$ & $16,78 \mathrm{~A}$ \\
\hline Aurora & $13,80 \mathrm{~b}$ & $13,50 \mathrm{~b}$ & $13,65 \mathrm{C}$ \\
\hline Mean of treatment & $15,03 \mathrm{~A}$ & $14,68 \mathrm{~A}$ \\
\cline { 2 - 4 } & & & \\
DS 5 \% Cultivar = 2.02-2.19 & & \\
DS 5 \% Treatment $=20.46-2.56$ & \\
DS 5 \% Interaction Cultivar $\times$ Mulch $=2.09-4.77$
\end{tabular}

a significant impact on fruit firmness, the lowest values for firmness were detected on 'Bluecrop' in pine bark treatment. Strik et al., in 2017 found inconsistent results for total soluble solids and fruit firmness during their study.

The highestcontent of TSS was found according to Table 7 in 'Bluecrop', in both treatments but there were no significant differences in pine bark or weed mat treatment. Similar results were obtained by Strik et al., in 2017 but as mentioned before without any consistency in results.

\section{Conclusions}

Results obtained in this study show that pine bark represents an interesting option for weed suppressing. Mulch application can maintain and improve organic matter in soil which may lead to an increased productivity if it is efficient at to weed suppressing.

More research is needed to evaluate the long-term effects that different mulches have on organic matter, soil composition, soil temperature, temperature stress, water evaporation. Aspects that are primarily responsible of yield and canopy growth.

Further studies must be made to conclude if pine bark affects soil $\mathrm{pH}$, possibly over a period of at least seven years.

There was a significant increase in $\mathrm{OM}$, which on long term will be extremely beneficial for the plant.

Weed mat treatment showed better results in berry weight and yield, this might be due to greater temperature under the weed mat but this aspect must be treated carefully as, high heat and not enough water is very detrimental to blueberry plants.

'Aurora' represents an interesting option for late season fruit, as it provides great yield, big berries and has a ripening season 5 days after classical 'Elliot'.

Every option can be the right option, in high dependency of material availability, quality, costs and short-medium strategy of the grower.

The best solution for plant is first the adding of weed mat, completed with pine bark, but further study must be made in order to determine if this strategy is cost effective.

The combination of pine bark and weed mat represents an option for organic commercial orchards.

\section{References}

1. Albert T, Karp K, Starast M and Paal T (2010). The effect of mulching and pruning on the vegetative growth and yield of the half-high blueberry. Agronomy Research, 8(1): 759-769.

2. Burkhard N, Lynch D, Percival D and Sharifi M (2009). Organic mulch impact on vegetation dynamics and productivity of highbush blueberry under organic production. HortScience 44: 688-696.

3. Cox J (2009). Comparison of plastic weedmat and woodchip mulch on low chill blueberry soil in New South Wales, Australia Acta Hort., 810475482

4. Duryea ML, English RJ and Hermansen LA (1999). A comparison of landscape mulches: Chemical, allelopathic, and decomposition properties. J. Arboric. 25: 88-96.

5. Julian JW, Strik HO, Larco, Bryla DR and Sullivan DM (2012). Costs of establishing organic BC northern highbush blueberry: Impacts of planting method, fertilization and mulch type. Hort.Sci. 47(7): 866-873.

6. Krewer G and Ruter J (2009). Fertilizing highbush blueberries in pine bark beds. 
7. Larco HO (2010). Effect of planting method, weed management, and fertilizer on plant of planting method, fertilization, and mulch type. HortScience 47: 1-8.

8. Larco HO, Strik BC, Bryla DR and Sullivan DM (2013) Mulch and fertilizer management practices for organic production of highbush blueberry. I. Plant growth and allocation of biomass during establishment. HortScience 48: 1-12.

9. Merwe van der JDP Lötze E, Schmeisser M (2012). The effects of organic and inorganic mulches on the yield and fruit quality of 'Cripps' Pink' apple trees after application of mulches, Acta.Hortic, 1076-11.
10. Oregon State University, Corvallis, OR, USA. http:// ir.library.oregonstate.edu/xmlui/

11. Strik BC (2006). Blueberry production and research trends in North America. Acta Hort. 715:173-183.

12. Strik BC (2014). Organic blueberry production systems - advances in research and industry. Acta Hort. 1017: 257-267.

13. Strik BC, Vance AJ, Bryla DR, Sullivan DM (2017). Organic Production Systems in Northern Highbush Blueberry: I. Impact of Planting Method, Cultivar, Fertilizer, and Mulch on Yield and Fruit Quality from Planting through Maturity Hort.Science 12179-17: 1201-1213. 